\title{
DISTRIBUTION AND TRANSFERABILITY OF PLASMIDS IN TRIMETHOPRIM RESISTANT URINARY ESCHERICHIA COLI
}

\author{
C. A. Kraft, D. J. Platt and M. C. Timbury \\ University Department of Bacteriology, Royal Infirmary, Castle Street, Glasgow \\ G4 OSF.
}

\begin{abstract}
SUmmary. Urinary isolates of Escherichia coli that were resistant to trimethoprim were collected in Glasgow Royal Infirmary during 1979 and 1980. Eighty-eight were resistant to trimethoprim $1024 \mu \mathrm{g} / \mathrm{ml}$ and $80(92 \%)$ were also resistant to sulphamethoxazole $1024 \mu \mathrm{g} / \mathrm{ml} ; 73 \%$ were multiresistant.

Plasmids were detected in $98 \%$ of strains and $60 \%$ carried two or more. Half of the isolates transferred trimethoprim resistance to $E$. coli $\mathrm{K} 12$ and $70 \%$ of these cotransferred resistance to sulphonamide although these markers were often not linked. Trimethoprim resistance was carried on 12 different plasmids, four of which also conferred sulphonamide resistance. All except two carried streptomycin resistance which suggests that $\operatorname{Tn} 7$ was probably present. The results are discussed in relation to current prescribing policy.
\end{abstract}

\section{INTRODUCTION}

Trimethoprim was marketed in Britain as a single agent in September 1979 after 10 years of use in combination with sulphamethoxazole. The incidence of trimethoprim resistance in bacteria increased during this period, particularly in hospital but also in general practice (Brogden et al., 1982). The spread of R-plasmids and transposons, particularly $\operatorname{Tn} 7$, which mediate resistance to the drug has caused concern (Barth et al., 1976; Datta and Richards, 1981).

An R-plasmid that conferred trimethoprim resistance was first described by Fleming, Datta and Grüneberg (1972) and trimethoprim resistance has since been found on R-plasmids of an increasing number of different incompatibility groups (Datta et al., 1980). There has also been an increase in non-transferable high level resistance to trimethoprim which may be chromosomally mediated (Towner et al., 1980).

We have collected trimethoprim resistant urinary coliforms isolated in 1979 and the early part of 1980 . This was around the time that trimethoprim became available on its own but while its use alone represented $<4 \%$ of the total amount of trimethoprim prescribed in Scotland (personal communication, Drug Information Centre, Ninewells Hospital, Dundee).

The aims of the study were: (i) to determine the proportion of trimethoprim 
resistance mediated by $\mathrm{R}$-plasmids, in the context of the plasmid complement of the clinical isolates; (ii) to investigate genetic linkage between plasmid-mediated trimethoprim and sulphamethoxazole resistance markers; and (iii) to obtain presumptive evidence of the contribution of $\operatorname{Tn} 7$ to trimethoprim resistance by the linked transfer of trimethoprim and low level streptomycin resistance. We report the distribution and transferability of plasmids in isolates of Escherichia coli that were resistant to trimethoprim.

The study was also intended to provide a baseline for data obtained after a period of use of trimethoprim alone in view of fears that removal of sulphonamide would lead to changes in trimethoprim resistance (British Medical Journal, 1980; Burman, 1980).

\section{MATERIALS AND METHODS}

Bacteria. The strains of enterobacteria studied were isolated in significant numbers $\left(\geqslant 10^{5}\right.$ organisms $/ \mathrm{ml}$ ) from specimens of urine from hospital patients and showed no inhibition zone around a disk containing trimethoprim $1.25 \mu \mathrm{g}$. They were collected from the routine diagnostic laboratory, Glasgow Royal Infirmary, between July 1979 and February 1980 and although efforts were made to obtain consecutive isolates some losses were unavoidable. The organisms were identified by the API 20E system (API Laboratory Products Ltd, Farnborough, Hants GU14 7QH).

The recipient strains used in transfer experiments were $E$. coli $\mathrm{K} 12$ J53-2 and J62-2 (Bachmann, 1972); both were resistant to rifampicin and were kindly provided by Professor N. Datta, Royal Postgraduate Medical School, London.

Media. Cystine-Lactose-Electrolyte Deficient (CLED) agar (Mast Laboratories Ltd, Derby Road, Bootle, Merseyside L20 1EA) was used for growth and maintenance of organisms and Isosensitest agar and broth (Oxoid) for sensitivity tests. Nutrient agar (Oxoid) and blood agar (Oxoid Columbia agar with $5 \%$ defibrinated horse blood) were used for growth of organisms for DNA extraction, and Brain Heart Infusion Broth (BHI; Oxoid) for conjugation experiments.

Antimicrobial sensitivity tests. Disk diffusion sensitivity tests were performed as described by Platt and Sommerville (1981). MICs were determined by an agar incorporation technique. Overnight broth cultures were diluted 1 in 100 in fresh Isosensitest broth. Isosensitest plates containing doubling dilutions of trimethoprim or sulphamethoxazole from 4-1024 $\mu \mathrm{g} / \mathrm{ml}$ were inoculated with $1 \mu \mathrm{l}$ of the bacterial suspensions by a multipoint inoculator (Denley, Billingshurst, Sussex). The MIC was the lowest concentration that prevented visible growth after overnight incubation at $37^{\circ} \mathrm{C}$.

Resistance transfer procedure. Donor and recipient strains were grown in $\mathrm{BHI}$ at $37^{\circ} \mathrm{C}$ overnight. Mixtures that contained $100 \mu$ lof the donor culture and $400 \mu \mathrm{l}$ of the recipient in $5 \cdot 0$ $\mathrm{ml}$ of fresh broth were sampled after incubation at $37^{\circ} \mathrm{C}$ for various periods from $30 \mathrm{~min}$ to $24 \mathrm{~h}$. Samples were plated by multipoint inoculator (Ackerman and Groot Obbink, 1979) on to CLED selection plates that contained rifampicin $50 \mu \mathrm{g} / \mathrm{ml}$, ascorbic acid $5 \mu \mathrm{g} / \mathrm{ml}$ and one of the following antibiotics: trimethoprim (Tp) $30 \mu \mathrm{g} / \mathrm{ml}$, sulphamethoxazole (Su) $100 \mu \mathrm{g} / \mathrm{ml}$, streptomycin (Sm) $15 \mu \mathrm{g} / \mathrm{ml}$, tetracycline (Tc) $10 \mu \mathrm{g} / \mathrm{ml}$, carbenicillin (Cb) $100 \mu \mathrm{g} / \mathrm{ml}$, chloramphenicol $(\mathrm{Cm}) 20 \mu \mathrm{g} / \mathrm{ml}$, or kanamycin $(\mathrm{Km}) 25 \mu \mathrm{g} / \mathrm{ml}$. Uridine $10 \mu \mathrm{g} / \mathrm{ml}$ was added to media that contained trimethoprim or sulphamethoxazole (Amyes and Smith, 1978). Control plates without rifampicin showed that trimethoprim- and sulphonamide-sensitive $E$. coli were inhibited by these media.

Potential transconjugants were harvested from the selection plates into $2 \mathrm{ml}$ of Isosensitest broth and simultaneously subcultured for purity and tested for homogeneity of resistance pattern by a disk sensitivity test. All cultures that appeared heterogeneous on sensitivity testing were presumed to contain more than one transconjugant type and these were separated and cloned. Plasmid transfer was confirmed by the demonstration of plasmid DNA in the transconjugants.

Detection of plasmid DNA. Plasmid DNA was extracted, separated by gel electrophoresis and the mol. wt determined as described previously (Platt and Sommerville, 1981). 


\section{RESULTS}

\section{Characterisation of the clinical isolates}

One hundred and ninety-two strains of enterobacteria were collected that were resistant to a $1 \cdot 25-\mu \mathrm{g}$ trimethoprim disk. One hundred and twenty-three were $E$. coli; 88 were highly resistant to trimethoprim (MIC $>1024 \mu \mathrm{g} / \mathrm{ml}$ ) and seven were moderately resistant (MIC $>64$ but $<1024 \mu \mathrm{g} / \mathrm{ml}$ ). Sixty-nine isolates belonged to other genera of enterobacteria and 20 of these were highly resistant. These comprised Citrobacter spp. (11 isolates), Klebsiella spp. (five isolates) and Proteus spp. (four isolates) and are not reported here because of the small numbers of each species and the difficulties of intergeneric transfer (Platt and Sommerville, 1981).

Those $E$. coli isolates that were resistant to $64 \mu \mathrm{g} / \mathrm{ml}$ but sensitive to $1024 \mu \mathrm{g} / \mathrm{ml}$ of trimethoprim did not transfer trimethoprim resistance, although all carried plasmids. Detailed characterisation was, therefore, restricted to the 88 highly resistant $E$. coli strains. They represented one isolate per patient unless repeat isolates differed. These

TABLE I

Antimicrobial resistance of clinical isolates of E. coli resistant to trimethoprim $1024 \mu \mathrm{g} / \mathrm{ml}$

\begin{tabular}{c|cc}
\hline $\begin{array}{c}\text { Number of antibiotics* } \\
\text { to which resistance was detected }\end{array}$ & $\begin{array}{c}\text { Number of } \\
\text { isolates } \\
\text { resistant }\end{array}$ & $(\%)$ \\
\hline 1 & 0 & $(0)$ \\
2 & 2 & $(2)$ \\
3 & 10 & $(11)$ \\
4 & 12 & $(14)$ \\
5 & 25 & $(28)$ \\
6 & 19 & $(22)$ \\
7 & 16 & $(18)$ \\
8 & 4 & $(5)$ \\
\hline
\end{tabular}

* Antibiotic concentration per disk: trimethoprim $1.25 \mu \mathrm{g}$, sulphamethoxazole $25 \mu \mathrm{g}$, streptomycin $10 \mu \mathrm{g}$, tetracycline $10 \mu \mathrm{g}$, ampicillin $10 \mu \mathrm{g}$, chloramphenicol $10 \mu \mathrm{g}$, kanamycin $30 \mu \mathrm{g}$ and nalidixic acid $30 \mu \mathrm{g}$.

strains were also resistant to one or more other antibiotics which included sulphamethoxazole, streptomycin, tetracycline, chloramphenicol, ampicillin, kanamycin and nalidixic acid. Resistance to three or more drugs was found in $86(98 \%)$ of the isolates; 64 isolates $(73 \%)$ were resistant to five or more and four $(5 \%)$ were resistant to all eight drugs (table I). All except four isolates (i.e., 84 strains) showed no zone around a $25 \mu \mathrm{g}$ sulphamethoxazole disk and the MIC of this drug for 80 isolates $(92 \%)$ was $>1024$ $\mu \mathrm{g} / \mathrm{ml}$.

On gel electrophoresis, plasmids were detected in $85(97 \%)$ of the isolates and $60 \%$ carried two or more. One isolate harboured seven plasmids. The frequency distribution of plasmid numbers in the isolates is shown in the figure (a).

\section{Transfer of resistance}

Fifty-four isolates transferred antimicrobial resistance to E. coli K12. Forty-four $(50 \%)$ transferred trimethoprim resistance and 31 of these also transferred sulphona- 

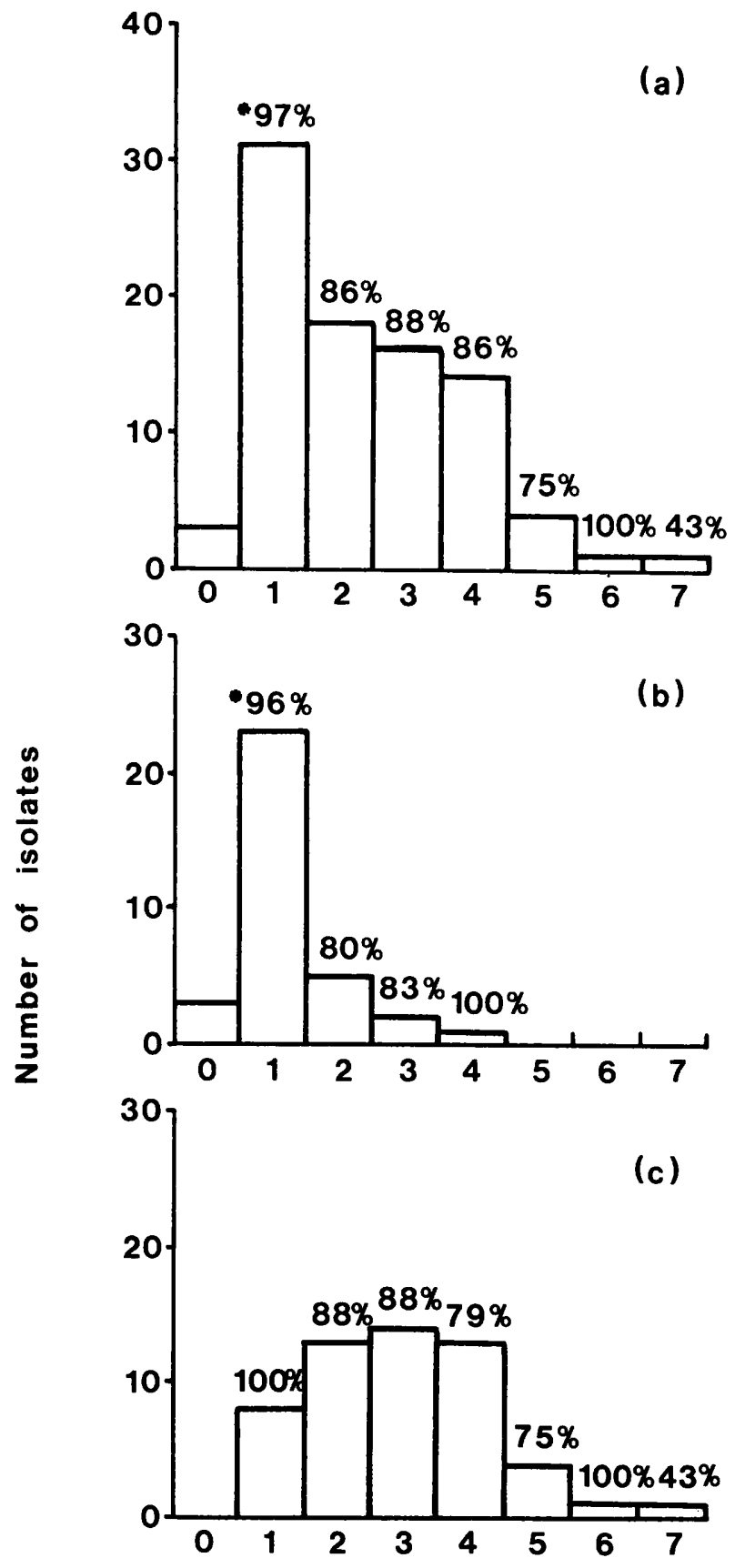

\section{Number of plasmids per isolate}

FIGURE.-Frequency distribution of plasmids in clinical isolates of E. coli resistant to trimethoprim 1024 $\mu \mathrm{g} / \mathrm{ml}$; (a) all isolates (88), (b) isolates that did not transfer antimicrobial resistance (34), (c) isolates that transferred antimicrobial resistance to $E$. coli K12 (54). Percentages indicate the proportion of plasmids of mol. $\mathrm{wt}>20 \times 10^{6}$. ${ }^{*}$ Only one isolate carried a single plasmid of mol. $\mathrm{wt}<15 \times 10^{6}$. 
TABLE II

Clinical isolates of E. coli that transferred resistance to trimethoprim and sulphamethoxazole to strains of E. coli K12

\begin{tabular}{l|cc}
\hline Drug resistance transferred & $\begin{array}{c}\text { Number of } \\
\text { isolates }\end{array}$ & $\mathbf{( \% )}$ \\
\hline Trimethoprim and sulphamethoxazole & 31 & $(35)$ \\
Trimethoprim but not sulphamethoxazole & 13 & $(15)$ \\
Sulphamethoxazole but not trimethoprim & 6 & $(7)$ \\
Other antimicrobials excluding & 4 & $(4)$ \\
trimethoprim and sulphamethoxazole & 34 & $(39)$ \\
None & 88 & $(100)$ \\
Total & \\
\hline
\end{tabular}

mide resistance. A further six isolates transferred sulphonamide resistance but not trimethoprim resistance and four isolates transferred resistance to other antimicrobials only (table II). Transfer of resistance to trimethoprim or sulphonamide was always accompanied by transfer of resistance to at least one other antimicrobial agent.

Sixteen different patterns of antimicrobial resistance were co-transferred with resistance to trimethoprim. The three most common patterns were $\mathrm{Tp} \mathrm{Su} \mathrm{Sm} \mathrm{Tc}$ (seven strains), Tp Su Sm Tc Ap (six strains) and Tp Su Sm Km Ap (five strains). The six strains that transferred resistance to sulphonamide but not to trimethoprim transferred four different patterns of resistance.

There was a marked tendency for resistance transfer to be associated with the presence of more than one plasmid in the isolate concerned. The frequency distribution of plasmid numbers in isolates that did not transfer resistance (figure, b) had a modal value of one plasmid per isolate whereas the distribution in isolates that contained conjugative plasmids showed a modal value of three plasmids per isolate (figure, c). The majority of the plasmids had mol. wts $>20 \times 10^{6}$.

\section{Characterisation of plasmids}

Samples of DNA extracted from transconjugants were examined by gel electrophoresis adjacent to extracts from their respective donors. Plasmid bands detected in samples from transconjugants were compared with those from the donors and correlated with the resistance markers transferred. When transconjugants acquired a single plasmid, which corresponded in size to one in the donor, it was possible to determine which resistance markers were carried by the plasmid concerned. Thus 37 isolates generated trimethoprim resistant transconjugants that carried a single plasmid; 14 transferred resistance to both trimethoprim and sulphonamide on the same plasmid whereas 23 isolates transferred trimethoprim resistance on plasmids that did not confer sulphonamide resistance. However, 11 of these 23 isolates also transferred sulphonamide resistance, but on a separate plasmid. The majority of such crosses also produced multiplasmid transconjugants that carried both resistance markers. Fourteen isolates transferred single plasmids that coded for resistance to sulphonamide but not to trimethoprim.

Twelve different trimethoprim resistance plasmids were distinguished on the basis of mol. wt and resistance pattern. Four different plasmids carried both trimethoprim 
TABLE III

Characteristics of plasmids that transferred resistance to trimethoprim, or to sulphamethoxazole without trimethoprim

\begin{tabular}{l|cc}
\hline & \multicolumn{2}{|c}{$\begin{array}{c}\text { Number of donor } \\
\text { isolates that } \\
\text { transferred } \\
\text { plasmid }\end{array}$} \\
\hline $\begin{array}{c}\text { Antimicrobial resistance* } \\
\text { pattern transferred }\end{array}$ & $\begin{array}{c}\text { Mean plasmid } \\
\text { mol. wt }\left(\times 10^{6}\right)\end{array}$ & 3 \\
Tp Sm & 35 & 8 \\
Tp Sm & 49 & 2 \\
Tp Sm & 60 & 1 \\
Tp Sm & 73 & 2 \\
Tp Tc & 34 & 3 \\
Tp Km & 64 & 3 \\
Tp Sm Tc & 48 & 1 \\
Tp Sm Km & 74 & 1 \\
Tp Su Sm Tc & 31 & 9 \\
Tp Su Sm Ap & 50 & 1 \\
Tp Su Sm Tc Ap & 46 & 1 \\
Tp Su Sm Tc Ap & 67 & 1 \\
Su Sm & 33 & 3 \\
Su Sm Tc & 78 & 3 \\
Su Sm Ap & 34 & 1 \\
Su Sm Ap & 64 & 5 \\
Su Sm Tc Ap & 62 & 66 \\
Su Sm Tc Ap Cm Km & 66 & \\
\hline
\end{tabular}

* See Methods for key to abbreviations.

and sulphonamide resistance whereas eight carried trimethoprim resistance without sulphonamide resistance. Six different plasmids transferred sulphonamide resistance without trimethoprim resistance (table III). With two exceptions, all the different trimethoprim resistance plasmids also carried streptomycin resistance.

Nineteen isolates generated transconjugants which could not all be analysed. In 10 instances, some resistance patterns appeared only in transconjugants that carried two or more plasmids so that the resistance markers involved could not be assigned to particular plasmids.

An example that demonstrates the complexity of these crosses is shown in table IV.

TABLE IV

Characterisation of E. coli K12 transconjugants obtained after conjugation with a trimethoprimresistant E. coli (GRI 1379)

\begin{tabular}{|c|c|c|c|c|c|c|c|c|c|}
\hline \multirow{3}{*}{\multicolumn{2}{|c|}{ Strain }} & \multirow{3}{*}{\multicolumn{2}{|c|}{$\begin{array}{c}\text { Antimicrobial resistance* } \\
\text { pattern }\end{array}$}} & \multicolumn{6}{|c|}{ Plasmids detected } \\
\hline & & & & & \multicolumn{5}{|c|}{ Mol. wt $\left(\times 10^{6}\right)$} \\
\hline & & & & Number & A & B & $\mathrm{C}$ & $\mathrm{D}$ & $\mathrm{E}$ \\
\hline \multicolumn{2}{|c|}{ Clinical isolate (donor) } & \multicolumn{2}{|c|}{ Tp Su Sm Ap Km Nal } & 5 & 31 & 48 & 53 & 72 & 90 \\
\hline \multirow{2}{*}{$\begin{array}{l}\text { E. coli } \mathrm{K} 12 \\
\text { transconjugant }\end{array}$} & $\left\{\begin{array}{l}1 \\
2 \\
3 \\
4\end{array}\right.$ & \multicolumn{2}{|c|}{$\begin{array}{l}\text { Tp Su Sm Ap } \\
\text { Su Sm Ap } \\
\text { Tp Su Sm Ap } \\
\text { Tp Su Sm Ap Km }\end{array}$} & $\begin{array}{l}1 \\
1 \\
2 \\
3\end{array}$ & $\begin{array}{l}31 \\
31 \\
31\end{array}$ & $\begin{array}{l}48 \\
\ddot{48} \\
48\end{array}$ & $\begin{array}{l}\cdots \\
\cdots \\
53\end{array}$ & $\begin{array}{l}\cdots \\
\cdots \\
\cdots\end{array}$ & $\begin{array}{l}\cdots \\
\cdots \\
\cdots\end{array}$ \\
\hline & $\begin{array}{l}5 \\
6 \\
7\end{array}$ & & $\begin{array}{l}\text { Sm Ap Km } \\
\text { Sm Ap Km } \\
\text { Sm Ap Km }\end{array}$ & $\begin{array}{l}2 \\
4 \\
2\end{array}$ & $\begin{array}{l}31 \\
31 \\
31\end{array}$ & $\begin{array}{l}\ldots \\
\ldots \\
\ldots\end{array}$ & $\begin{array}{l}53 \\
53 \\
\ldots\end{array}$ & $\begin{array}{l}72 \\
72\end{array}$ & $\begin{array}{l}90 \\
\ldots\end{array}$ \\
\hline
\end{tabular}

* See Methods. 
One clinical isolate (GRI 1379) carried five plasmids (A-E) that transferred to $E$. coli K12. Seven transconjugants were isolated which differed either in antimicrobial resistance pattern, or the combination of plasmids carried, or both. Two conjugative plasmids, A and B, carried Su Sm Ap and Tp Su Sm Ap respectively. Plasmids C and $D$ cotransferred with plasmid $A$. By inference they carried $\mathrm{Km}$ and $\mathrm{Tp} \mathrm{Km}$ respectively. However, three transconjugants were at variance with this interpretation because they appeared to have lost resistance markers without a detectable change in the mol. wt of the plasmids acquired. Attempts to segregate these plasmids further were unsuccessful.

In another six crosses, transconjugants showed plasmid bands that did not correspond with those in the donor. One transconjugant acquired resistance to trimethoprim and streptomycin in the absence of a detectable plasmid and eight crosses each produced at least two transconjugants with different patterns of resistance but with a plasmid of the same mol. wt.

\section{Discussion}

An association between trimethoprim resistance and multiple antibiotic resistance has been noted previously (Datta et al., 1980). In the investigation reported here, $98 \%$ of the highly resistant isolates from Glasgow Royal Infirmary were resistant to three or more drugs and $73 \%$ were resistant to at least five. Moreover, isolates that transferred resistance tended to be those that carried multiple plasmids, possibly because an increase in the number of plasmids concomitantly increases the probability that one will be conjugative. Possession of a conjugative plasmid would also make more likely the mobilisation of non-conjugative plasmids and this might explain why many transconjugants acquired several plasmids. Most plasmids had a mol. wt $>20 \times 10^{6}$ - the smallest known to be conjugative (Broda, 1979) - so that lack of resistance transfer cannot be attributed to the absence of plasmids of adequate size.

Half of our highly resistant isolates transferred trimethoprim resistance-a proportion twice as high as that reported by Hamilton-Miller, Gooding and Brumfitt (1981) for isolates collected in London during 1978-79. Our finding that only high levels of resistance to trimethoprim were transferable agrees with that of earlier workers (Amyes, Emmerson and Smith, 1978; Datta et al., 1980). However, Towner and Pinn (1981) have described a conjugative plasmid that conferred a moderate degree of resistance to trimethoprim.

Resistance to trimethoprim was carried on several plasmids which appeared to be different on the basis of their mol. wt and resistance patterns. With two exceptions, the plasmids that coded for trimethoprim resistance also carried streptomycin resistance; much of the trimethoprim resistance described in the present study may have been coded for by $\operatorname{Tn} 7$. This finding is consistent with the dissemination of $\operatorname{Tn} 7$ among different plasmids (Datta, Nugent and Richards, 1981). The failure of half of our isolates to transfer high-level trimethoprim resistance is similar to the results reported by Towner et al. (1980). A possible explanation is that, in these isolates, trimethoprim resistance could have been encoded by a transposon located in the bacterial chromosome. This interpretation is supported by the finding that three isolates transferred all their plasmids but failed to transfer resistance to $\mathrm{Tp}, \mathrm{Sm}$, and $\mathrm{Su}-$ markers known to be associated with transposons. Alternatively, the trimetho- 
prim resistance in some strains could have been coded by non-conjugative plasmids because plasmids were found in all except three of the highly resistant isolates that failed to transfer resistance.

It is important to correlate the plasmid bands in donor and transconjugants because fragmentation, cointegration and other DNA rearrangements may accompany transfer (Willshaw, Smith and Anderson, 1979). A distinction must also be made between cotransfer of resistance markers and their genetic linkage. In our experiments $\mathrm{Tp}$ and $\mathrm{Su}$ were transferred together from $70 \%$ of the isolates that transferred $\mathrm{Tp}$. However, only 14 isolates transferred these markers on a single plasmid whereas 23 isolates transferred $\mathrm{Tp}$ on a plasmid that lacked the Su determinant, an observation made also by Datta and Richards (1981). Thus, the frequent transfer of $\mathrm{Tp}$ and $\mathrm{Su}$ together is a result of the acquisition of multiple plasmids by transconjugants.

The isolates described here were collected around the time when trimethoprim first became available as a single agent after 10 years of use in combination with sulphonamide, and most were resistant to both drugs. The results demonstrate, however, that these markers segregate under appropriate conditions of selection. Salter (1982) has pointed out that sulphonamide resistance has been common in enterobacteria for many years so that the use of co-trimoxazole had effectively applied selection pressure with trimethoprim alone for many strains. This would account for the segregation observed here.

It is clearly important to monitor the effects of changing selection pressures that may result from large scale alterations in prescribing policies. However, this will only be possible if detailed attention is given to the genetic linkage of markers as well as to the distinction between transferable and chromosomal resistance mechanisms. Study of the segregation of trimethoprim and sulphonamide resistance markers should, therefore, provide a more sensitive indicator of the effect of the change from co-trimoxazole to trimethoprim than simply measurement of the incidence of trimethoprim resistance.

\section{REFERENCES}

ACKerman, V. P. AND Groot Obbink, D. J. 1979. Screening for transferable antibiotic resistance in the clinical laboratory. Journal of Antimicrobial Chemotherapy, 5, 167-172.

AmYES, S. G. B., EMmERSON, A. M. AND SMITH, J. T. 1978. R factor mediated trimethoprim resistance: result of two three-month clinical surveys. Journal of Clinical Pathology, 31, $850-854$.

Amyes, S. G. B. AND Smith, J. T. 1978. Trimethoprim antagonists: effect of uridine in laboratory media. Journal of Antimicrobial Chemotherapy, 4, 421-429.

BachmanN, B. J. 1972. Pedigrees of some mutant strains of Escherichia coli K12. Bacteriological Reviews, 36, 525-557.

Barth, P. T., Datta, N., Hedges, R. W. and Grinter, N. J. 1976. Transposition of a deoxyribonucleic acid sequence encoding trimethoprim and streptomycin resistances from R483 to other replicons. Journal of Bacteriology, 125, 800-810.

BRITISH MEDICAL JOURNAL (LEADING ARTICLE) 1980. Bacterial resistance to trimethoprim. British Medical Journal, 281, 571-572.

BRodA, P. 1979. Plasmids. W. H. Freeman and Co., Oxford, p.14.

Brogden, R. N., Carmine, A. A., Heel, R. C., Speight, T. M., and Avery, G. S. 1982. Trimethoprim: A review of its antibacterial activity, pharmacokinetics and therapeutic use in urinary tract infections. Drugs, 23, 405-430.

BuRman, L. G. 1980. Resistance to trimethoprim. Lancet, 1, 1409. 
DATTA, N. AND 7 OTHERS. 1980. Distribution of genes for trimethoprim and gentamicin resistance in bacteria and their plasmids in a general hospital. Journal of General Microbiology, 118, 495-508.

Datta, N., Nugent, M. and Richard, H. 1981. Transposons encoding trimethoprim or gentamicin resistance in medically important bacteria. Cold Spring Harbor Symposia on Quantitative Biology XLV, 45-51.

DatTa, N. AND Richards, H. 1981. Trimethoprim resistant bacteria in hospital and in the community: spread of plasmids and transposons. In Molecular biology, pathogenicity, and ecology of bacterial plasmids, edited by S. B. Levy, R. C. Clowes and E. L. Koenig, Plenum Press, New York, pp. 21-30.

Fleming, M. P., DatTa, N. AND GrüNEBERG, R. N. 1972. Trimethoprim resistance determined by R-factors. British Medical Journal, 1, 726-728.

HAMilTON-MilleR, J. M. T., GoOding, A., BrumfitT, W. 1981. Resistance to trimethoprim in 1978-79 compared with 1973-75. Journal of Clinical Pathology, 34, 439-442.

Platt, D. J. AND Sommerville, J. S. 1981. A simple method for the detection of resistance plasmids in Serratia species by transfer to members of the genus Enterobacter. Journal of Antimicrobial Chemotherapy, 8, 145-152.

SALTER, A. J. 1982. Trimethoprim-sulfamethoxazole: an assessment of more than 12 years of use. Reviews of Infectious Diseases, 4, 196-236.

Towner, K. J., Pearson, N. J., Pinn, P. A. AND O'Grady, F. 1980. Increasing importance of plasmid mediated trimethoprim resistance in enterobacteria: two six month clinical surveys. British Medical Journal, 280, 517-519.

TOWNER, K. J. AND PINN, P. A. 1981. A transferable plasmid conferring only a moderate level of resistance to trimethoprim. FEMS Microbiology Letters, 10, 271-272.

Willshaw, G. A., Smith, H. R. AND Anderson, E. S. 1979. Application of agarose gel electrophoresis to the characterization of plasmid DNA in drug resistant enterobacteria. Journal of General Microbiology, 114, 15-25. 